\title{
Assessment of the Non-linear Response of the fSampEn on Simulated EMG Signals
}

\author{
Luis Estrada-Petrocelli, Senior Member, IEEE, Manuel Lozano-García, Raimon Jané, Senior Member, \\ IEEE and Abel Torres, Senior Member, IEEE
}

\begin{abstract}
Fixed sample entropy (fSampEn) is a promising technique for the analysis of respiratory electromyographic (EMG) signals. Its use has shown outperformance of amplitudebased estimators such as the root mean square (RMS) in the evaluation of respiratory EMG signals with cardiac noise and a high correlation with respiratory signals, allowing changes in respiratory muscle activity to be tracked. However, the relationship between the fSampEn response to a given muscle activation has not been investigated. The aim of this study was to analyze the nature of the fSampEn measurements that are produced as the EMG activity increases linearly. Simulated EMG signals were generated and increased linearly. The effect of the parameters $r$ and the size of the moving window $N$ of the fSampEn were evaluated and compared with those obtained using the RMS. The RMS showed a linear trend throughout the study. A non-linear, sigmoidal-like behavior was found when analyzing the EMG signals using the fSampEn. The lower the values of $r$, the higher the non-linearity observed in the fSampEn results. Greater moving windows reduced the variation produced by too small values of $r$.
\end{abstract}

Clinical Relevance - Understanding the inherent non-linear relationship produced when using the fSampEn in EMG recordings will contribute to the improvement of the respiratory muscle activation assessment at different levels of respiratory effort in patients with respiratory conditions, particularly during the inspiratory phase.

\section{INTRODUCTION}

The electrical activity generated during a muscle contraction $(\mathrm{EMG})$ reflects the level and pattern of effort exerted during a physical activity. The study of EMG has made it possible to assess the condition of the musculoskeletal system in presence of a disease, sparking interest in the use of this technique. Several applications have arisen from the study of EMG activity. Its use has contributed to control upper-limb exoskeletons for people with arm disabilities [1]. In the respiratory system, the EMG recording is related to the activity during inspiration. Respiratory EMG signal can be recorded in different locations of the trunk such as the costal diaphragm [2], [3] in the parasternal zone [4] or also in accessory muscles

This work was supported in part by the CERCA Program/Generalitat de Catalunya, in part by the Secretaria d'Universitats i Recerca de la Generalitat de Catalunya under Grant GRC 2017 SGR 01770, in part by the Spanish Ministry of Science, Innovation and Universities under Grant RTI2018098472-B-I00 MCIU/AEI/FEDER, UE. L. Estrada-Petrocelli, M. LozanoGarcía, A. Torres, and R. Jané are with the Institut de Bioenginyeria de Catalunya (IBEC), the Barcelona Institute of Science and Technology (BIST), Universitat Politècnica de Catalunya (UPC) BarcelonaTech, of neck [5]. Its evaluation has been of clinical utility in the study of respiratory muscle activity in healthy subjects [2]-[5] and in patients with respiratory conditions [6], [7]. During the 2019 pandemic of severe acute respiratory syndrome coronavirus 2 (SARS-CoV-2) causing COVID-19 disease, diaphragm EMG measurements were investigated in combination with respiratory support devices [8], in addition to monitoring respiratory muscle function during recovery from COVID-19 disease [9]. As for respiratory EMG recordings, these measurements are susceptible to bioelectrical interferences such as the electrical activity of the heart (ECG) or muscles nearby the recording area, limiting their evaluation.

For the study of respiratory EMG signals, the root mean square (RMS) has been widely used in clinical practice for the analysis of the amplitude of such signals, however, this technique is sensitive to noise of an impulsive nature such as ECG. A promising technique for the analysis of respiratory EMG signals is the fixed sample entropy (fSampEn) [2]. This technique allows for the quantification of variations in signal complexity and variations in signal amplitude, being more sensitive to amplitude variations of more complex signal components as EMG while being less sensitive to deterministic components such as ECG.

The fSampEn has been used in the study of respiratory EMG recordings in healthy subjects and in patients with chronic obstructive pulmonary disease at different levels of inspiratory load [2]-[4], [7], [10] as well as for the analysis of EMG signals recorded for proportional myoelectric control in high level amputee patients after a targeted muscle reinnervation surgery [11]. In such studies, the performance of fSampEn has been shown to be superior to that of the RMS, avoiding unnecessary filtering of EMG signals and preserving the signal spectrum.

Despite the proven utility of the fSampEn for the study of electromyographic signals, the relationship that may exist between fSampEn measurements and muscle activation has not been addressed. In the present study, simulated EMG signals without impulsive noise were evaluated with the aim of assessing the relationship between the use of the fSampEn and simulated activation. Furthermore, the response of the different fSampEn input parameter were evaluated.

Campus Diagonal-Besòs, Av. d'Eduard Maristany, 10-14, building C, 5th floor, 08930, Barcelona, Spain and with the Biomedical Research Networking Centre in Bioengineering, Biomaterials and Nanomedicine (CIBER-BBN) (e-mails: \{lestrada, mlozano, rjane, atorres\}@ibecbarcelona.eu). M. Lozano-García, R. Jané and A. Torres are also with the UPC-BarcelonaTech. L. Estrada-Petrocelli is also with the Facultad de Ingeniería, Universidad Latina de Panamá, Apartado Postal 0823-00923, Panama City, Republic of Panama. 
Ramp increase | slope: 1.5
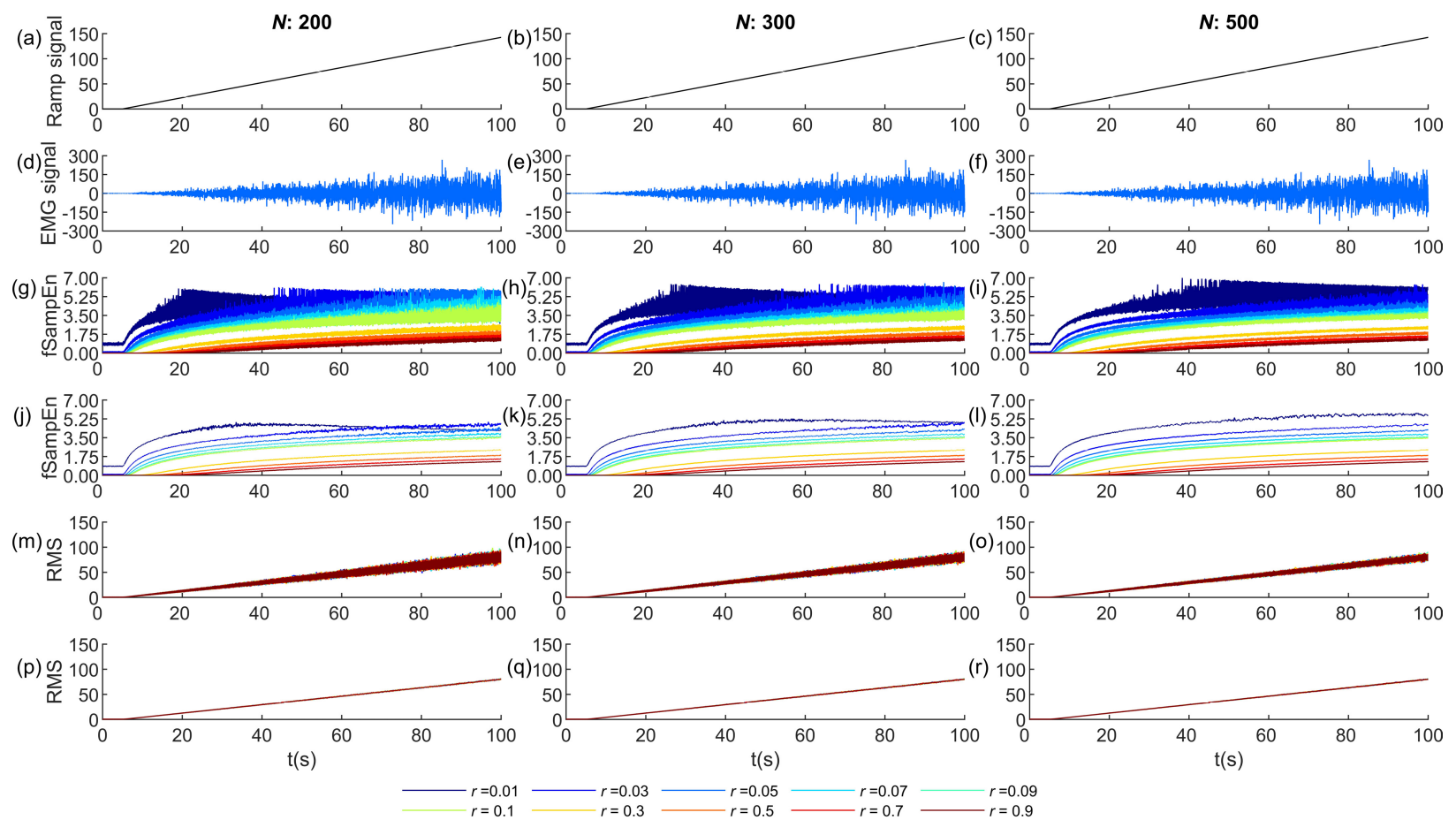

Figure 1. Simulated EMG signals. (a-c) Signal activation model using a ramp function. (d-e) EMG signal model. (g-i) fSampEn time series obtained after using the fSampEn technique on the different simulated EMG signals for each $r$ value. (j-1) Average of the generated fSampEn time series for each $r$ value. (m-o) RMS time series obtained after evaluating the RMS technique on the different simulated EMG signals. (p-r) Average of RMS time series.

\section{MATERIAL AND METHODS}

\section{A. Signal Activation Model}

A ramp function was used as model signal that ideally represents changes in the level of muscle activation in a linear way. This model consists of two parts. The first part, which represents the resting activity (baseline) and last for 5 seconds. The second part, which describes the linear change in activation level due to an inspiratory effort over time up to 100 seconds. The slope of the signal was varied four times at 0.5 , $1,1.5$ and 2.

\section{B. EMG Signal Model}

To evaluate the performance of the fSampEn technique, a simulated EMG signal was generated using white Gaussian noise. The simulated EMG signal is free of noise. Fifty simulated EMG signals were generated for each increase in the slope of the activation signal resulting in a total of 200 simulated EMG signals. A sampling frequency of $1000 \mathrm{~Hz}$ was used.

\section{EMG Signal Processing}

Simulated EMG signals were analyzed using the fSampEn and the RMS. fSampEn estimates signal complexity and amplitude variation of time-series. Three input parameters must be specified: the embedding dimension $m$, the tolerance $r$, and the window size $N$. The fSampEn evaluates segments of $m$ consecutive observations that are compared within the same tolerance region $r$ in a moving window of length $N$. The parameter $r$ is fixed for each moving window $N$ and was calculated as the standard deviation of the analyzed [2], [10]. The parameter $m$ was set to 1 . This study evaluated the effect of the tolerance $r$ value and the window size $N$ on the performance of fSampEn measures. The tolerance $r$ was evaluated 10 times at $0.01,0.03,0.05,0.07,0.09,0.1,0.3,0.5$, 0.7 and 0.9 times the standard deviation of the whole EMG signal model. The window size $N$ was evaluated three times at 200,300 and 500 samples with a $10 \%$ overlap between consecutive analysis windows. As a result, a total of 6000 fSampEn time series were analyzed. Similarly, the amplitude of the 50 simulated EMG signals for each of the 4 slopes of the signal activation model were measured using the RMS and running the 3 moving windows, giving a total of 600 RMS time series.

\section{Data Analysis}

fSampEn time series obtained for a given set of signal activation model slope, $r$ and $N$ parameters were averaged. Likewise, RMS time series for a given set of slope and $N$ parameter were averaged. Then, fSampEn and RMS time series and the signal activation model were normalized to the 0 to 1 interval for comparison. The relationship between the normalized fSampEn time series and the normalized EMG activation model was compared to assess any non-linearities that may exist when fSampEn was applied to the simulated EMG signals. A sigmoidal model was proposed to study the non-linear curves obtained after evaluating the normalized fSampEn time series. Curve-fitting was applied to the first fSampEn normalized time series segments using non-linear least squares. The Gompertz model was proposed to characterize the fSampEn curves. This model is made up of the following parameters: $a$ which represents the upper asymptote of the curve, $b$ determines the displacement along 

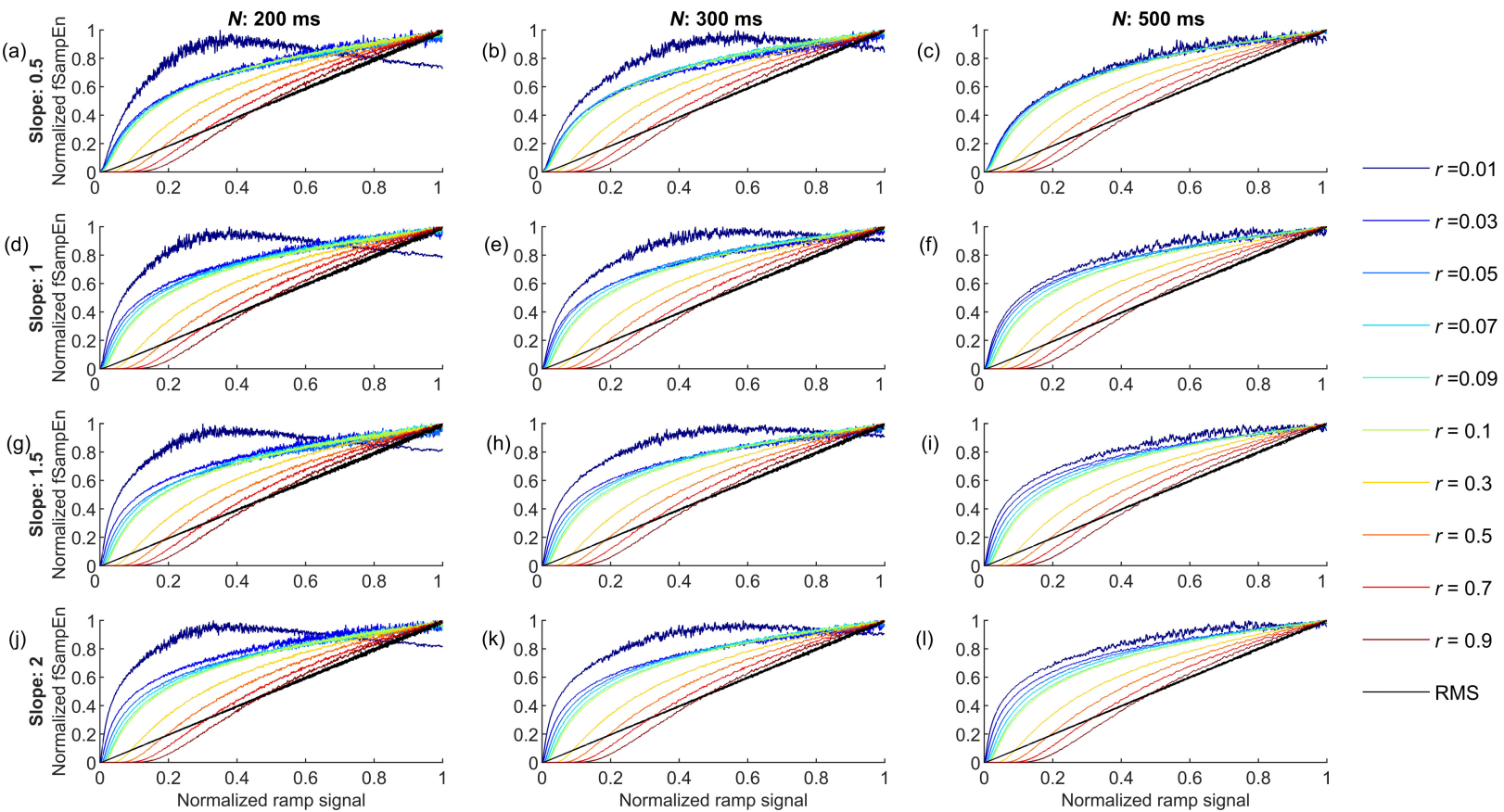

Figure 2. Comparison between normalized fSampEn time series, normalized RMS time series and the normalized signal activation model by varying the slope model by (a-c) 0.5 , (d-f) 1 , (g-i) 1.5 and (j-1) 2 . fSampEn time series are shown at different values of $r$. The normalized fSampEn and normalized RMS time series were calculated at three moving window sizes $N: 200,300$ and 500 samples.

the signals and $c$ which indicates the exponential decay rate of the relative growth rate of the normalized fSampEn timeseries. We reported the parameters $b$ and $c$ evaluated up to 0.1 in the normalized ramp signal. Simulated EMG signals were processed and analyzed using custom-developed software on MATLAB (v. R2021b, Natick, MA, USA).

\section{RESULTS}

Fig. 1 (a-c) shows the signal activation model (ramp) with a slope of 1.5 and (Fig. (d-f)) the corresponding generated EMG signal. It is shown the $50 \mathrm{fSampEn}$ time series obtained for each parameter $r$, using a moving analysis window $N$ of 200, 300 and 500 samples (Fig. 1 (g-i)). The average of the 50 simulated fSampEn time series for each $r$ value and moving window $N$ are shown in Fig. 1 (j-1). Similarly, Fig. 1 (m-o) shows the 50 RMS time series generated for each moving window and Fig. 1 (p-r) shows the average of the RMS time series. In general, both the fSampEn and RMS time series increased with increasing simulated EMG activity. The effect of fSampEn on simulated EMG signals can be seen as the parameter $r$ and the moving window size $N$ are varied. The lower the values of the parameter $r$ the greater the offset in the fSampEn. Also, the larger the amplitude of the simulated EMG signal, the greater the variation in the fSampEn time series. Particularly, a $r$ value of 0.01 resulted in a greater variation in the fSampEn time series decreasing their measurements after about $20 \mathrm{~s}$. Conversely, $r$ values from 0.03 to 0.9 showed a non-linear and stable increase, especially during the initial seconds, as observed in the averaged fSampEn time series compared to signal activation model. Thereafter, the increase seen in the fSampEn time series exhibited a slower and linear trend. The higher the parameter $r$, the smaller the increase observed in the fSampEn time series. The larger the moving window size $N$, the smoother the fSampEn time series, reducing the pronounced non-linearities, especially for very small values of $r$. On the other hand, the RMS time series increased in a linear fashion showing greater variation at higher values of simulated EMG amplitude. The averaged RMS time series showed that this linear trend was similar to that shown by the linear activation model.

Fig. 2 shows the non-linear relationship between the normalized fSampEn time series to the normalized signal activation model and the linear relationship of the normalized RMS time series to the normalized signal activation model. Two phases were identified in the fSampEn curves: a lag phase (below 0.1 in the normalized signal activation model) and an exponential phase. Values of $r$ greater than 0.3 showed a longer lag phase and a slower exponential growth phase, while values less than 0.3 showed a shorter lag phase but a faster exponential growth phase. The influence of slopes was not observed in the normalized fSampEn time series. Fig. 3 shows a boxplot of $b$ and $c$ parameters of the Gompertz model for all slopes analyzed, at different $r$ and $N$ values of the fSampEn. The parameter $b$ of the Gompertz model increased slightly up to values of $r$ less than 0.3 and then increased more steeply. The parameter $c$ of the Gompertz model decreased slightly up to a value of $r$ less than 0.3 , and then decreased.

\section{DISCUSSION}

Respiratory EMG activity is positively correlated and increases with the force-generating capacity of the respiratory muscles. For convenience, amplitude-based estimators such as RMS have been widely used for the analysis of EMG activity, but these are sensitive to the presence of ECG-like impulsive noise. In contrast to the classical RMS amplitude estimator, the fSampEn, an entropy-based technique that quantifies signal complexity variations and signal amplitude variations. fSampEn has the ability to track changes in respiratory EMG activity due to changes produced by respiratory effort, being less affected by impulsive noise (ECG) [2]. Previously, 

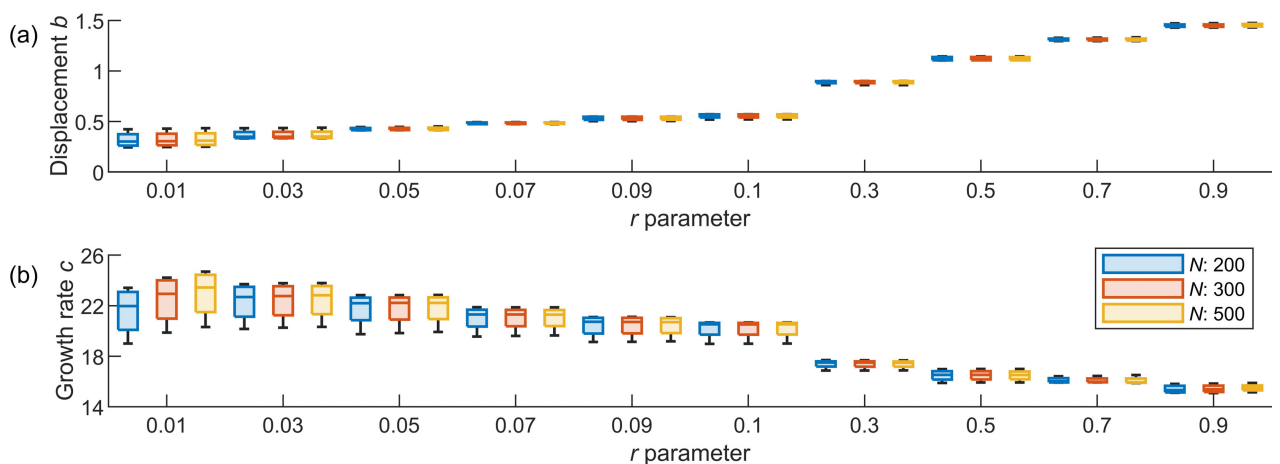

Figure 3. Boxplot comparison. The Gompertz's parameter $b$ represents the displacement along the normalized signal activation model and $c$ determines the exponential decay rate of the relative growth rate of the normalized fSampEn time-series.

fSampEn has shown a high level of correlation as compared to other respiratory signals such as mouth pressure [2]-[4], [10]. Although the robustness of fSampEn has been demonstrated for the study of electromyographic signals, few studies have investigated whether the use of fSampEn shows a linear trend or not. In this study, we have investigated the non-linear behavior of the fSampEn response on simulated EMG signals that increase linearly (ramp function). The fSampEn was very sensitive to changes in the parameter $r$. Values of $r$ higher than 0.3 produced a non-linear response with a higher lag phase and a slower growth phase. Conversely, the smaller the values of $r$, the shorter the lag phase and the greater the growth phase. The above indicates that very small values of $r$ would lead to large non-linearities and potential instabilities in the fSampEn response when evaluating a linearly increasing EMG signal. As for the moving window of analysis $N$, large windows sizes produced a smoothing effect resulting in a reduction of variability observed at very small values of $r$ such as 0.01 . Interestingly, there were no evident changes in the response of fSampEn to different slope values of the activation model (Fig. 2). Contrary to the use of the fSampEn, the RMS response showed a linear behavior when compared to the signal activation model, falling on the identity line.

In the present study, we have observed that the fSampEn exhibited a non-linear behavior. Zhang et al. studied the relationship between the use of fSampEn on low-amplitude surface EMG signals in amputee subjects and ECG noise-free RMS amplitude [11]. They found that a log-type fit best describes the relationship between fSampEn and RMS. This result would enhance the calibration of the myoelectric control of a prosthesis that processes EMG signals using the fSampEn [11]. However, the effect that parameter $r$ and window size $N$ might have on the non-linear response of the fSampEn in the analysis of EMG signals has not been considered. In our study, it was found that the normalized time series fSampEn showed a sigmoidal behavior in its initial part when compared to the normalized signal activation model. For the study of this nonlinear trend in the fSampEn response, we have proposed the use the Gompertz model. This non-linear model provided a reasonable approximation for the study of normalized fSampEn time series during their initial period. Values below an $r$ of 0.3 showed greater values in the parameters $b$ and $c$ of the Gompertz model revealing a lower phase lag and higher exponential growth, respectively. Assessment of the nonlinear effect of using the fSampEn would improve the measurement of inspiratory muscle activation on respiratory EMG signals at different levels of respiratory effort.

\section{CONCLUSION}

The study of non-linearities arising when evaluating respiratory EMG signals using the fSampEn could improve the assessment of respiratory muscle function in patients with different respiratory conditions. This preliminary study was performed on basic simulated EMG signals. Future work should be conducted to assess the effect that fSampEn has on more comprehensive simulated EMG models and on EMG recordings at different types of muscle activation with and without ECG.

\section{REFERENCES}

[1] E. Trigili et al., "Detection of movement onset using EMG signals for upper-limb exoskeletons in reaching tasks," J. Neuroeng. Rehabil., vol. 16, no. 1, pp. 1-16, 2019.

[2] L. Estrada, A. Torres, L. Sarlabous, and R. Jané, "Improvement in neural respiratory drive estimation from diaphragm electromyographic signals using fixed sample entropy," IEEE J. Biomed. Heal. Informatics, vol. 20, no. 2, pp. 476-485, Mar. 2016.

[3] M. Lozano-García et al., "Noninvasive assessment of inspiratory muscle neuromechanical coupling during inspiratory threshold loading," IEEE Access, vol. 7, pp. 183634-183646, Dec. 2019.

[4] M. Lozano-García et al., "Noninvasive Assessment of Inspiratory Muscle Neuromechanical Coupling during Inspiratory Threshold Loading," Sensors, 2021.

[5] L. Estrada-Petrocelli et al., "Evaluation of Respiratory Muscle Activity by Concentric Ring Electrodes," IEEE Trans. Biomed. Eng., vol. 68 , no. 3, pp. 1005-1014, 2021.

[6] C. C. Reilly et al., "Neural respiratory drive, pulmonary mechanics and breathlessness in patients with cystic fibrosis," Thorax, vol. 66, no. 3, pp. 240-246, Mar. 2011.

[7] D. Blanco-Almazán et al., "Combining Bioimpedance and Myographic Signals for the Assessment of COPD during Loaded Breathing," IEEE Trans. Biomed. Eng., vol. 68, no. 1, pp. 298-307, Jan. 2020.

[8] A. Noto et al., "Performance of EasyBreath Decathlon Snorkeling mask for delivering continuous positive airway pressure," Sci. Rep., vol. 11, no. 1, pp. 1-8, 2021.

[9] R. F. D'Cruz et al., "Parasternal electromyography as a measure of respiratory muscle function in patients recovering from severe COVID-19 pneumonia," in Thorax, 2021, vol. 76, no. Suppl 1, pp. A218-A219.

[10] L. Estrada, A. Torres, L. Sarlabous, and R. Jané, "Influence of parameter selection in fixed sample entropy of surface diaphragm electromyography for estimating respiratory activity," Entropy, vol. 19, no. 9, p. 460, Sep. 2017.

[11] X. Zhang, X. Ren, X. Gao, X. Chen, and P. Zhou, "Complexity analysis of surface EMG for overcoming ECG interference toward proportional myoelectric control," Entropy, vol. 18, no. 4, pp. 1-12, Mar. 2016. 